\title{
Microbial Decontamination: Understanding the Concepts and Types of Decontamination Methods, and Evaluating Their Usefulness
}

\author{
Ahmed Elkhatat ${ }^{1}$ \\ ${ }^{1}$ Qatar University
}

August 5, 2020

\begin{abstract}
Effective microbial decontamination of healthcare equipment, tools and surfaces is imperative in order to prevent the transmission of pathogens among patients, medical staff and visitors. The terminology used to describe microbial decontamination processes, including "sanitizing", "sanitizing", "antiseptic" and "sterilization", is frequently used interchangeably, and the evaluation parameters are often misunderstood. Hence, the main objective of this review is to comprehensively explain the concepts of microbial decontamination, highlight the different types of microbial decontamination in terms of effectiveness of decontamination and how they perform with respect to microbial resistance.
\end{abstract}

\section{What is Decontamination?}

Decontamination is a process in which pathogens are removed, inactivated or destroyed (Veerabadran \& Parkinson, 2010). A pathogen is a microbe that causes disease. The term microbe encompasses all microorganisms, which are living entities, such as bacteria, fungi, mold, yeast and algae, as well as non-living entities such as viruses Decontamination is the technique or process of removing, inactivating or killing pathogens to make an environment clean and safe (Fraise, Maillard, \& Sattar, 2008; Godbey, 2014; McDonnell, 2017).

\section{Types of Microbial Decontamination}

Terms used to refer to decontamination processes are commonly used interchangeably, including "sanitizing", "disinfecting", "antiseptic" and "sterilization". However, there are significant differences in the level of decontamination resulting from these processes. The Environmental Protection Agency (EPA) has defined three categories of microbial treatments based on the level of effectiveness of decontamination; sanitizers, disinfectants and sterilants (EPA).

Sanitizing is the least effective decontamination method. Sanitizers clean surfaces of pathogens, without completely killing microbial populations that are considered to be safe from a public health perspective. Sanitizers can be applied on both inanimate (non-living) surfaces and live tissues (e.g. skin)(Mahmood et al., 2020).

Disinfectants provide a higher level of decontamination than sanitizing. The EPA includes antiseptics within the category of disinfectants. Disinfectants and antiseptics may contain the same microbial pesticide, which 
is the chemical agent that inactivates or kills vegitative microorganisms. The difference between the two is that disinfectants are used for inanimate surfaces, while antiseptics are applied onto live tissue.

The best decontamination method is sterilizing, which kills both vegetative microorganisms and their spores.

\section{Resistance of Microorganisms to Decontamination}

Microorganisms differ greatly in their ability to tolerate destruction by physical or chemical means. As demonstrated in Fig. 1 vegetative bacteria, viruses, fungi, and mycobacteria are often considered the least resistant to decontamination and can usually be reduced to a sanitary level by sanitizers or destroyed by disinfection methods. Bacterial endospores and other protective shell structures such as oocysts and eggs are the most resistant type of pathogen and are only killed by sterilization processes. The potent power of physical or chemical sterilization processes destroys the robust protective layers of these endospores and shell structures, destroying their genomes (Lai et al., 2003; Riesenman \& Nicholson, 2000; Setlow, 2006; Swenson, 2012).

Endospores are the most resistant type of pathogen and extreme sterilization methods are required to destroy them. Endospores are a pathogen's method of surviving in extreme conditions. Endospores of Bacillus species have demonstrated the ability to resist and survive extreme conditions, such as highly acidic environments, prolonged exposure to high temperatures, non-ionizing and ionizing radiation, as well as strong antibiotics including ampicillin, cephalothin and oxacillin (Berg \& Grecz, 1970; Byrne, Dunne, \& Bolton, 2006; Clavel, Carlin, Lairon, Nguyen-The, \& Schmitt, 2004; Schlegelova, Babak, Brychta, Klimova, \& Napravnikova, 2003; Setlow, 1995).

Spores have multiple protective layers, which act as barriers, and accounts for their extreme resistance to decontamination. The first barrier is the external layer, which consists of either an exosporium or a spore coat. The exosporium is composed of a number of different proteins, while a spore coat consists of both proteins and glycoproteins. The external layer has the ability to filter and detoxify many environmental contaminants (Lai et al., 2003; Setlow, 2006). The barrier beneath the external layer is the cortex, which is formed of a thick layer of peptidoglycans. The cortex protects the core from destruction by organic solvents. The third barrier, situated beneath the cortex, is the cell wall, which is again composed of peptidoglycans. Beneath the cell wall is a cell membrane, which safeguards the central core. The final barrier is the central core, which consists of small acid-soluble binding proteins (SASP) that protect the DNA. Spores are able to survive for many years until favorable conditions arise, at which point they can then develop into vegetative cells (Driks, 2002; Riesenman \& Nicholson, 2000; Setlow, 2006).

Protozoa are microscopic unicellular organisms, which are widespread in almost every habitat. Some species of protozoa are commensal and are not pathogenic to their hosts, whereas others are pathogenic and may cause a range of diseases from mild in severity to life-threatening, such as malaria. Infection from protozoa can be caused by contaminated water, food, and soil via sporulated oocysts passed in the feces of the host. Protozoal oocysts, which are an essential stage of the life cycle of protozoa ((CDC), 2004; Yaeger., 1996) have a high level of resistance to chemical and physical decontamination treatments, due to their protective membrane or hardy cell wall that is composed of two layers of over $90 \%$ protien. The outer layer of the oocyst wall contains mainly lipids-free quinone-tanned proteins, whilst the inner layer consists of a lipid-protein matrix (Mai et al., 2009).

Helminth cause parasitic infections that lead to the tropical disease, Helminthiasis. The female helminth worm deposits the eggs into the host in a process known as oviposition. Adult helminth can deposit up to 700,000 eggs, six times a day. The helminth eggs are highly resistant to chemical and physical decontamination methods, because of their layered structure which provides resistance under several conditions. There are three basic layers which consist of an outer proteinic layer, followed by a chitinous layer, and then an inner lipoidal layer (Jimenez, 2007). The persistence of helminth ova is the main constraint for the reuse of water and wastewater (WHO, 2006). 
Fungi and fungal spores exhibit high resistance to decontamination treatments (Ma \& Bibby, 2017). Waterborne fungi are considered responsible for environmental problems such as turbidity, odor and mycotoxin emissions, in addition to waterborne diseases caused byAspergillus spp . and Penicillium spp . (Curtis, Lieberman, Stark, Rea, \& Vetter, 2009; Hageskal, Knutsen, Gaustad, de Hoog, \& Skaar, 2006; Oliveira, Barreto Crespo, \& Pereira, 2020; Pereira et al., 2009).

Bacteria can be classified as Gram positive (GP) or Gram negative (GN), based on the structure of the cell wall. The cell wall of GP bacteria is characterized by a thick peptidoglycan layer with no outer lipid membrane, while the peptidoglycan layer is thin in GN bacteria, and supported with an outer lipid membrane (Gram, 1884). 90-95\% of GN bacteria are pathogenic and are often implicated in severe disease, such as Cholera caused by Vibrio cholerae, whilst most GP bacteria are non-pathogenic (Abe et al., 2010; Alexandraki \& Palacio, 2010). Although these pathogenic GN bacteria show more resistance to antibiotics than GP strains, they are more susceptible to decontamination methods and can be easily decontaminated. Comparatively, GP bacteria have more resistance to decontamination methods, but tend to be less harmful to humans (Howie, Alfa, \& Coombs, 2008; Traverse \& Aceto, 2015).

Mycobacteria has its name derived from the latin word myco, which refers to fungus, because mycobacteria have been observed to grow in a mold-like manner when cultivated in laboratories. Mycobacteria are responsible for serious diseases in humans, such as tuberculosis and leprosy (Ryan \& Ray, 2004). Mycobacteria show a high level of resistance to chemical and physical decontamination methods due to their cell wall, which is composed of hydrophobic mycolic acid and peptidoglycan layers that are interconnected by a highly branched polysaccharide (arabinogalactan), which represents about $80 \%$ of the cell wall (Alderwick, Harrison, Lloyd, \& Birch, 2015; Jackson, 2014).

The extracellular form of a virus that spreads from one organism to another is called a virion. In contrast to other microorganisms, viruses can not be considered as living organisms as they lack their own metabolism. A virion consists of a viral genome (containing both DNA and RNA), which is enclosed in a protein capsid that provides protection to the genome. Viruses can be classified into two types; enveloped and non-enveloped, according to their cell membrane. Viruses are referred to as enveloped when the protein capsid is surrounded by a membrane ("envelope"), which is composed of a lipid bilayer studded with virus-coded proteins in the shape of spikes or knobs, called peplomers. The role of the biological membrane is to protect the virus against attack from the host immune system. Viruses without a membrane are known as non-enveloped or "naked" viruses. Contrary to what one would expect, non-enveloped viruses are the most resistant to decontamination methods, and smaller non-enveloped viruses are more resistant than larger ones. This is because outer lipid bilayer "envelopes" can be easily neutralized by various chemical and physical agents, and a virion is only infectious if it is fully intact. Hence, if the envelope is destroyed, a virion is no longer infectious (Gelderblom, 1996; Howie et al., 2008; Traverse \& Aceto, 2015). 


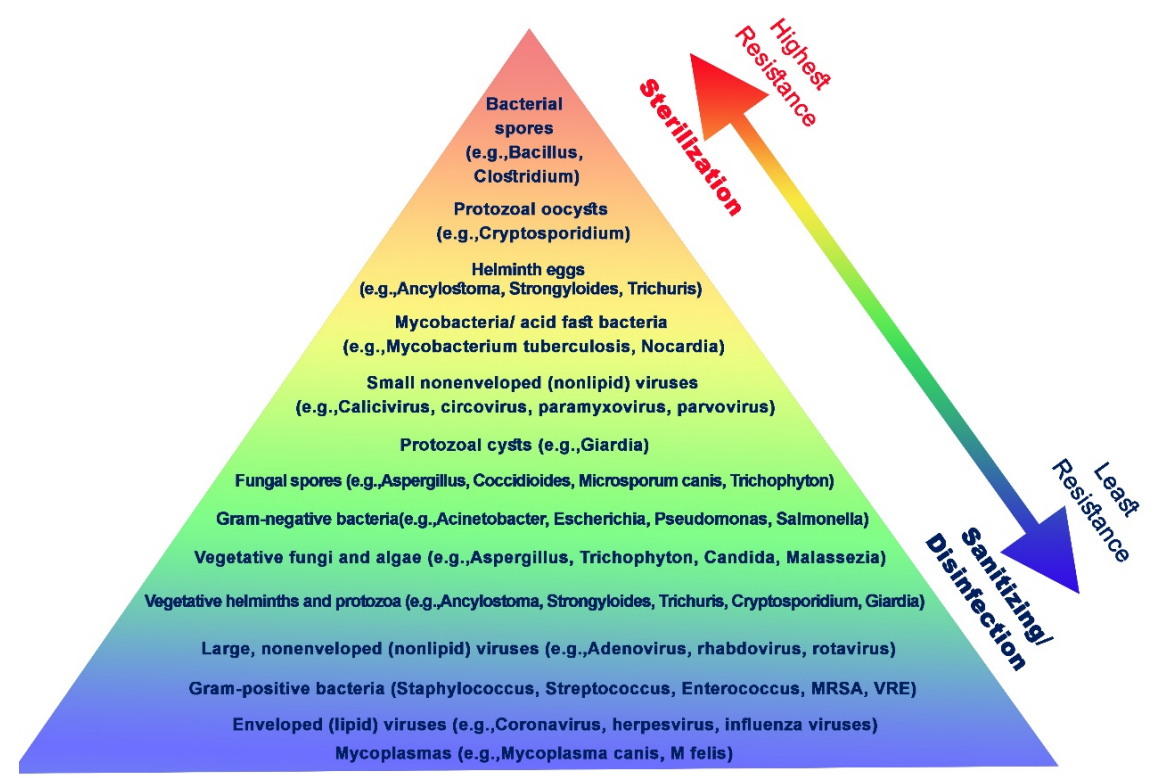

Figure 1 demonstrates the increasing order of resistance different microorganisms have to different decontamination methods (drawn based on data given from (Traverse \& Aceto, 2015)).

\section{Evaluation of Decontamination Methods}

Decontamination methods are generally evaluated in terms of efficacy, effectiveness and efficiency. Efficacy is the measurement of the ability of the treatment to carry out the desired effect under "ideal", controlled circumstances (such as in a laboratory experiment, i.e. 'in vitro' ). In layman's terms, efficacy measures whether the decontamination method works or not. Effectiveness measures the ability of the treatment to carry out the desired effect under "real" circumstances (such as in healthcare practice, i.e. 'in vivo '). In other words, effectiveness measures whether the decontamination method works within the intended setting. Efficiency evaluates the treatment with respect to the resources it consumes, so it measures whether the decontamination method is good value (Haynes, 1999; Marley, 2000).

The level of decontamination can be assessed using "D", "LR" and "SAL" values. D-value is an abbreviation of "Decimal Reduction Time" (DRT), and is used to assess a method or technology that is capable of inactivating $90 \%$ of a population of microorganisms in a test (Conley, 2014a). The measurement can be a time, a temperature, a pressure, a chemical, a dose or a technique. For example, if a pressure of 2 bar results in a $\mathrm{D}$-value of 0.5 minutes, this means that 30 seconds of 2 bar pressure is sufficient to inactivate $90 \%$ of microorganisms in the test. It should be noted that D values are measured on a logarithmic scale, and $90 \%$ decontamination is referred to as a 1-log reduction (1 LR). A 2-log reduction (2 LR) indicates that $99 \%$ of a population has been inactivated, a 3-log (3 LR) reduction refers to $99.9 \%$ decontamination, and so on.

Although killing or inactivation of $99.9 \%$ of microbes seems impressive, this percentage means that thousands 
of pathogens might still survive. Thus, it is useful to consider another assessment measure, SAL, which stands for Sterility (or Security) Assurance Level. (Lerouge, 2012; Wilson \& Nayak, 2019). SAL measures the number of remaining contaminated items among those which have undergone decontamination (Conley, 2014b). In other words, the SAL is the probability of there being a non-sterile unit or surviving microorganism after the sterilization process. The required assurance of sterility is typically a SAL of $10^{-6}$ (Enzinger, 1990; Wilson \& Nayak, 2019), which means that for every million units that have undergone sterilization, one might remain unclean. Achieving a SAL of $10^{-12}$ is considered an overkill (Sandle, 2013).

Although both SAL and LR values use a logarithmic base of 10 , it is imperative to emphasize that the SAL is not the same measurement as the LR. In other words, a value of 6 LR does not necessary equate to a SAL of $10^{-6}$. Indeed, the value of total LR required to achieve a SAL of $10^{-6}$ is a summation of both the LR required to have a population of one unit, and the $6 \mathrm{LR}$ further required to achieve a SAL of $10^{-6}$. For example, for a population of one million microorganisms, a 6 LR results in only one microorganism remaining. Additionally, the probability of having one surviving microorganism for every million unit is a SAL of $10^{-6}$. Thus the total LR is $10^{-12}$ as shown in Fig 2. Another example to explain the calculation is; if a D-value (i.e. $1 \mathrm{LR}$ ) for a microbe is about 20 seconds for specific decontamination conditions, then, after exposure to the same conditions for two minutes (120 seconds), the microbial decontamination will reach 6 LR, and consequently, four minutes of decontamination are needed to reach a $12 \mathrm{LR}$, which is equivalent to a SAL of $10^{-6}$. A further example is: if a decontamination method results in 2 LR (99\% decontamination) which results in 1 colony forming unit (CFU) remaining from an initial CFU of 100 within 60 seconds; to achieve a SAL of $10^{-6}$, the total LR for both microbial reduction and sterility assurance level values must be added together (i.e. $2+6=8$ ), thus $8^{*} 60$ seconds or 8 minutes are required. Understanding the concepts of these calculations is very important in order to be able to assess decontamination levels correctly.

Another useful test dedicated to assess a chemical decontamination method is Breakthrough Survival (BTS), which measures the failure of a chemical biocide to kill $10^{6}$ of vegetative organisms within 1 minute. This time duration was chosen as it is the expected time for a chemical biocide to dry once applied to an inanimate surface (Rutala, Peacock, Gergen, Sobsey, \& Weber, 2006).

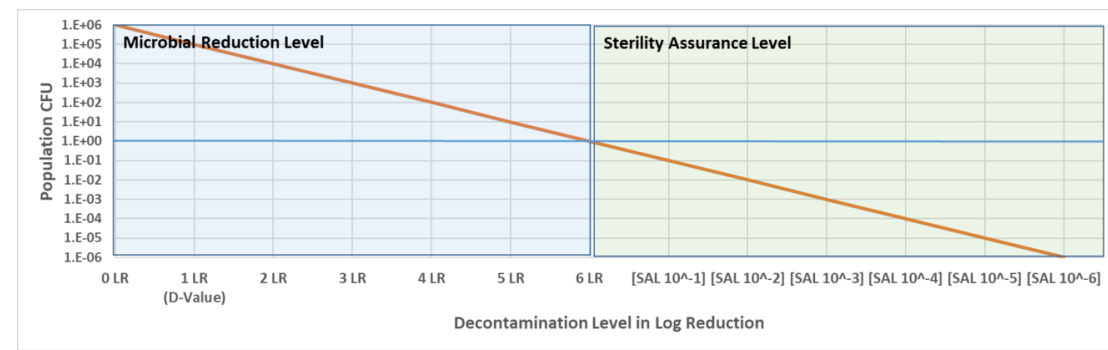

Figure 2. Level of decontamination in respect to log reduction (LR) and sterility assurance level (SAL) measures.

\section{Monitoring of Decontamination Methods}

Biological and chemical indicators are used to monitor the lethality of a sterilization process and ensure the effectiveness of sterilization. They are also used to routinely monitor a sterilizer's performance according to practices developed and published by the "Association for the Advancement of Medical Instrumentation" (AAMI), the "Association for peri-Operative Registered Nurses" (AORN) and the "Centers for Disease Control" (CDC).

Biological indicators (BI) contain large number of highly resistant spores of Geobacillus stearothermophilus . Destroying and killing of these spores in the BI by the tested sterilization processes implies that the steriliza- 
tion process is effective enough to kill other potential pathogens. BIs are commercially available as test kits, and they are used to assess the sterility level of water, food containers, and medical and surgical tools and instruments in hospital rooms. When the test kit is incubated, the spores of G.Stearothermophilusgerminate in the kit and produce $\alpha$-glucosidase enzymes that react with the fluorescent media (4-methyl-umbelliferyl$\alpha$-D-glucopyranoside) in the kit and produces a fluorescent signal, which is then detected by the detector in the incubator. The advantage of BIs is that they are quite quick tests, only requiring 20 minutes for both incubation and detection ([BSI], 2014a; ANS, 2017; Gordon, 2013; Swenson, 2012).

In contrast to BIs, chemical indicators (CIs) do not contain resistant spores, and instead use special chemicals or pigments that change physical properties or color when specific environmental conditions have been attained. As such, they are able to monitor decontamination methods based on the fulfillment of one or more of the parameters required for a satisfactory sterilization process. This physical or chemical change is interpreted as a pass or fail result. For example, when using steam for sterilization such as in an autoclave, a solid CI that converts to liquid upon exposure to steam can be used to confirm the quality of sterilization. When pigments are used, they chemically react with some critical parameters of the sterilization process and consequently the color changes to its endpoint color, indicating that the parameters for sterilization have been met. ([BSI], 2001, 2014b; ANS, 2017).

\section{Conclusion}

Understanding the concepts and types of decontamination methods, and evaluating their usefulness is imperative in order to prevent transmission of potential pathogens and improve the shelf life of commodities. As microbes differ greatly in their ability to tolerate destruction by physical or chemical means, it is important to choose a suitable decontamination method in order to achieve the required level of decontamination. Sanitizing, which is the least effective decontamination method, reduces the number of pathogens to a sanitary level. Disinfectants and antiseptics provide a higher level of decontamination, as they inactivate or kill vegetative microbes. The best decontamination method is sterilizing, which kills both vegetative microbes and their spores. The level of decontamination can be assessed using "D", "SAL" and "LR" values, and monitored with biological and chemical indicators.

\section{Acknowledgements}

The publication of this article was funded by the Qatar National Library.

\section{References}

(CDC), C. f. D. C. a. P. (2004). Outbreak of Cyclosporiasis Associated with Snow Peas - Pennsylvania, 2004 . Retrieved from MMWR Morb Mortal Wkly Rep.: https://www.cdc.gov/mmwr/preview/mmwrhtml/mm5337a6.htm

[BSI], B. S. I. (2001). BS EN 867-5. Non-biological systems for use in sterilizers. Specification for indicator systems and process challenge devices for use in performance testing for small sterilizers Type B and Type S. In.

[BSI], B. S. I. (2014a). BS EN ISO 11138e1. Sterilization of health care products e Biological indicators. Part 1: General requirements. In.

[BSI], B. S. I. (2014b). BS EN ISO 11140-1. Sterilization of health care products. Chemical indicators. General requirements. In.

Abe, R., Oda, S., Sadahiro, T., Nakamura, M., Hirayama, Y., Tateishi, Y., . . . Hirasawa, H. (2010). Gramnegative bacteremia induces greater magnitude of inflammatory response than Gram-positive bacteremia. Crit Care, 14 (2), R27. doi:10.1186/cc8898

Alderwick, L. J., Harrison, J., Lloyd, G. S., \& Birch, H. L. (2015). The Mycobacterial Cell Wall-Peptidoglycan and Arabinogalactan.Cold Spring Harb Perspect Med, 5 (8), a021113. doi:10.1101/cshperspect.a021113 
Alexandraki, I., \& Palacio, C. (2010). Gram-negative versus Gram-positive bacteremia: what is more alarmin(g)? Crit Care, 14 (3), 161. doi:10.1186/cc9013

ANS, A. N. S. (2017). ANSI/AAMI ST79:2017 Comprehensive guide to steam sterilization and sterility assurance in health care facilities. In.

Berg, P. E., \& Grecz, N. (1970). Relationship of dipicolinic acid content in spores of Bacillus cereus T to ultraviolet and gamma radiation resistance. J Bacteriol, 103 (2), 517-519.

Byrne, B., Dunne, G., \& Bolton, D. J. (2006). Thermal inactivation of Bacillus cereus and Clostridium perfringens vegetative cells and spores in pork luncheon roll. Food Microbiol, 23 (8), 803-808. doi:10.1016/j.fm.2006.02.002

Clavel, T., Carlin, F., Lairon, D., Nguyen-The, C., \& Schmitt, P. (2004). Survival of Bacillus cereus spores and vegetative cells in acid media simulating human stomach. J Appl Microbiol, 97 (1), 214-219. doi:10.1111/j.1365-2672.2004.02292.x

Conley, C. A. (2014a). D-Value. In Encyclopedia of Astrobiology : Springer-Verlag Berlin Heidelberg.

Conley, C. A. (2014b). Sterility Assurance Level. In Encyclopedia of Astrobiology : Springer-Verlag Berlin Heidelberg.

Curtis, L., Lieberman, A., Stark, M., Rea, W., \& Vetter, M. (2009). Adverse Health Effects of Indoor Molds. Journal of Nutritional \& Environmental Medicine, 14 (3), 261-274. doi:10.1080/13590840400010318

Driks, A. (2002). Maximum shields: the assembly and function of the bacterial spore coat. Trends in Microbiology, 10 (6), 251-254. doi:10.1016/s0966-842x(02)02373-9

Enzinger, R. M. (1990). Sterility Assurance from post- filling heat treatment. PDA Journal of Parenteral Science and Technology $44,294-295$.

EPA. What are Antimicrobial Pesticides? Retrieved from https://www.epa.gov/pesticide-registration/whatare-antimicrobial-pesticides

Fraise, A. P., Maillard, J.-Y., \& Sattar, S. (2008). Principles and Practice of Disinfection, Preservation and Sterilization (4th ed.): Wiley-Blackwell.

Gelderblom, H. R. (1996). Structure and Classification of Viruses. In S. Baron (Ed.), Medical Microbiology (4 ed.).

Godbey, W. T. (2014). Microbial Killing. In An Introduction to Biotechnology (pp. 143-164).

Gordon, P. E. (2013). P389: A rapid biological indicator for sterility assurance. Antimicrobial Resistance and Infection Control, 2 (Suppl 1). doi:10.1186/2047-2994-2-s1-p389

Gram, C. (1884). Ueber die isolirte Farbung der Schizomyceten in Schnitt-und Trockenpraparaten. Fortschritte der Medicin, 2 , 185-189.

Hageskal, G., Knutsen, A. K., Gaustad, P., de Hoog, G. S., \& Skaar, I. (2006). Diversity and significance of mold species in Norwegian drinking water. Appl Environ Microbiol, 72 (12), 7586-7593. doi:10.1128/AEM.01628-06

Haynes, B. (1999). Can it work? Does it work? Is it worth it? The testing of healthcareinterventions is evolving. BMJ, 319 (7211), 652-653. doi:10.1136/bmj.319.7211.652

Howie, R., Alfa, M. J., \& Coombs, K. (2008). Survival of enveloped and non-enveloped viruses on surfaces compared with other micro-organisms and impact of suboptimal disinfectant exposure. J Hosp Infect, 69 (4), 368-376. doi:10.1016/j.jhin.2008.04.024

Jackson, M. (2014). The mycobacterial cell envelope-lipids. Cold Spring Harb Perspect Med, 4 (10). doi:10.1101/cshperspect.a021105 
Jimenez, B. (2007). Helminth ova removal from wastewater for agriculture and aquaculture reuse. Water Sci Technol, 55 (1-2), 485-493. doi:10.2166/wst.2007.046

Lai, E. M., Phadke, N. D., Kachman, M. T., Giorno, R., Vazquez, S., Vazquez, J. A., . . . Driks, A. (2003). Proteomic analysis of the spore coats of Bacillus subtilis and Bacillus anthracis. J Bacteriol, 185 (4), 1443-1454. doi:10.1128/jb.185.4.1443-1454.2003

Lerouge, S. (2012). Introduction to Sterilization: Definitions and Challenges. In S. Lerouge \& A. Simmons (Eds.), Sterilisation of Biomaterials and Medical Devices (pp. 1-19): Elsevier, 2012.

Ma, X., \& Bibby, K. (2017). Free chlorine and monochloramine inactivation kinetics of Aspergillus and Penicillium in drinking water. Water Res, 120 , 265-271. doi:10.1016/j.watres.2017.04.064

Mahmood, A., Eqan, M., Pervez, S., Alghamdi, H. A., Tabinda, A. B., Yasar, A., . . . Pugazhendhi, A. (2020). COVID-19 and frequent use of hand sanitizers; human health and environmental hazards by exposure pathways. Sci Total Environ, 742 , 140561. doi:10.1016/j.scitotenv.2020.140561

Mai, K., Sharman, P. A., Walker, R. A., Katrib, M., De Souza, D., McConville, M. J., . . . Smith, N. C. (2009). Oocyst wall formation and composition in coccidian parasites. Mem Inst Oswaldo Cruz, 104 (2), 281-289. doi:10.1590/s0074-02762009000200022

Marley, J. (2000). Efficacy, effectiveness, efficiency. Australian Prescriber, 23 (6), 114-115. doi:10.18773/austprescr.2000.131

McDonnell, G. E. (2017). Antisepsis, Disinfection, and Sterilization: Types, Action, and Resistance (2nd Edition ed.): ASM Press.

Oliveira, B. R., Barreto Crespo, M. T., \& Pereira, V. J. (2020). Small but powerful: Light-emitting diodes for inactivation of Aspergillus species in real water matrices. Water Res, 168, 115108. doi:10.1016/j.watres.2019.115108

Pereira, V. J., Basilio, M. C., Fernandes, D., Domingues, M., Paiva, J. M., Benoliel, M. J., . . San Romao, M. V. (2009). Occurrence of filamentous fungi and yeasts in three different drinking water sources. Water Res, 43 (15), 3813-3819. doi:10.1016/j.watres.2009.05.024

Riesenman, P. J., \& Nicholson, W. L. (2000). Role of the spore coat layers in Bacillus subtilis spore resistance to hydrogen peroxide, artificial UV-C, UV-B, and solar UV radiation. Appl Environ Microbiol, 66 (2), 620626. doi:10.1128/aem.66.2.620-626.2000

Rutala, W. A., Peacock, J. E., Gergen, M. F., Sobsey, M. D., \& Weber, D. J. (2006). Efficacy of hospital germicides against adenovirus 8, a common cause of epidemic keratoconjunctivitis in health care facilities.Antimicrob Agents Chemother, 50 (4), 1419-1424. doi:10.1128/AAC.50.4.1419-1424.2006

Ryan, K. J., \& Ray, C. G. (2004). Sherris medical microbiology : an introduction to infectious diseases / Kenneth J. Ryan, C. George Ray, editors. (K. J. Ryan \& C. G. Ray Eds. 4 ed.). New York: McGraw-Hill.

Sandle, T. (2013). Steam sterilisation. In T. Sandle (Ed.), Sterility, Sterilisation and Sterility Assurance for Pharmaceuticals (pp. 93-109): Woodhead Publishing.

Schlegelova, J., Babak, V., Brychta, J., Klimova, E., \& Napravnikova, E. (2003). The prevalence of and resistance to antimicrobial agents of Bacillus cereus isolates from foodstuffs. Veterinarni Medicina-UZPI (Czech Republic), 48 (11), 331-338.

Setlow, P. (1995). Mechanisms for the prevention of damage to DNA in spores of Bacillus species. Annu Rev Microbiol, 49 , 29-54. doi:10.1146/annurev.mi.49.100195.000333

Setlow, P. (2006). Spores of Bacillus subtilis: their resistance to and killing by radiation, heat and chemicals. J Appl Microbiol, 101 (3), 514-525. doi:10.1111/j.1365-2672.2005.02736.x 
Swenson, D. (2012). Factors and principles: the science of sterilization. Biomed Instrum Technol, Suppl, 33-36. doi:10.2345/0899-8205-12.1.33

Traverse, M., \& Aceto, H. (2015). Environmental cleaning and disinfection. Vet Clin North Am Small Anim Pract, 45 (2), 299-330, vi. doi:10.1016/j.cvsm.2014.11.011

Veerabadran, S., \& Parkinson, I. M. (2010). Cleaning, disinfection and sterilization of equipment. Anaesthesia $\&$ Intensive Care Medicine, 11 (11), 451-454. doi:10.1016/j.mpaic.2010.08.005

WHO. (2006). WHO guidelines for the safe use of wasterwater excreta and greywater (Vol. 1): World Health Organization.

Wilson, A. J., \& Nayak, S. (2019). Disinfection, sterilization and disposables. Anaesthesia 8 Intensive Care Medicine, 20 (11), 603-608. doi:10.1016/j.mpaic.2019.09.013

Yaeger., R. G. (1996). Protozoa: Structure, Classification, Growth, and Development. In S. Baron (Ed.), Medical Microbiology (4 ed.). Galveston (TX). 